\title{
ARTICLE
}

\section{Self and suffering in Indian thought: implications for clinicians}

\author{
Swaran P. Singh [1]
}

Swaran P. Singh is Professor of Social and Community Psychiatry in the Centre of Mental Health and Wellbeing Research at Warwick Medical School, Coventry, UK.

Correspondence Swaran P. Singh. Email: s.p.singh@warwick.ac.uk

First received 27 Nov 2021 Final revision 5 Jan 2022 Accepted 6 Jan 2022

\section{Copyright and usage}

(C) The Author(s), 2022. Published by Cambridge University Press on behalf of the Royal College of Psychiatrists. This is an Open Access article, distributed under the terms of the Creative Commons Attribution licence (https://creativecommons. org/licenses/by/4.0/), which permits unrestricted re-use, distribution, and reproduction in any medium, provided the original work is properly cited.

\section{SUMMARY}

The four main Indian religions - Hinduism, Buddhism, Jainism and Sikhism - have several shared concepts about self and suffering, which are salient to the world-view of the followers of these faiths. Understanding the concepts of mind, self and suffering in these faiths can help clinicians build better rapport and gain deeper understanding of the inner world of patients of these faiths. This article highlights the broad cultural and religious beliefs of these groups, with the hope that increased knowledge among clinicians might lead to better therapeutic engagement.

\section{LEARNING OBJECTIVES}

After reading this article you will be able to:

- demonstrate knowledge about the basic belief system of four main Indian religions Hinduism, Buddhism, Jainism and Sikhism

- understand the concepts of mind, self and suffering in these religions and how these may be reflected in phenomenology and patient assessment

- sensitively and appropriately explore spirituality in the therapeutic relationship with patients of these faiths.

\section{KEYWORDS}

Anthropology; philosophy; transcultural psychiatry; patients; spirituality.

'Know the self (atma) as the Lord of the chariot, the body (sarira) as the chariot itself, the discriminating intellect (buddhi) as the charioteer and the mind (manas) as the reins. The senses, say the wise, are the horses; selfish desires are the roads they travel. When the self is confused with the body, mind and senses, they point out, he seems to enjoy pleasure and suffer sorrow. When one lacks discrimination and his mind is undisciplined, the senses run hither and thither like wild horses. But they obey the rein like trained horses when one has discrimination and has made the mind one-pointed [...] The senses derive from objects of sense-perception, sense objects from mind, mind from intellect, intellect from ego, ego from undifferentiated consciousness, and consciousness from Brahman.'

(Katha Upanishad, part of Yajurveda, one of the four Vedas (Easwaran 2007a).

This article gives a brief overview of four Indian religions - Hinduism, Buddhism, Jainism and
Sikhism - and summarises their shared beliefs and individual tenets, focusing primarily on the concepts of self and suffering. Between them, these faiths constitute the oldest (Hinduism) and one of the youngest (Sikhism) organised religions in the world that are followed by about $22 \%$ of the global population (Hackett 2012) and are collectively known as the Dharmic religions. A common origin from the Vedic culture means that the latter three (Buddhism, Jainism and Sikhism) share several conceptual and thematic similarities with Hinduism. Article 25 of the Indian constitution classifies adherents to all four faiths as Hindus, but some consider this lumping together of distinct religious and philosophical traditions as a form of institutional bias (Singh 2005a). There are ongoing debates in India about legally recognising each as a distinct religion with its respective laws, but these matters are not within the scope of this article. The most recent national data show that about $2.4 \%$ of the UK population belongs to one of these faiths (Office for National Statistics 2013).

Consciousness and its relationship with other mental functions, including self, is also beyond the scope of this article. In summarising over three millennia of philosophical, intellectual and cultural developments it is not possible to cover all the subtle, nuanced and complex distinctions between these faiths and their subsects. This article does not aim to 'idealise the exotic' or caricature the Western as 'reductionistic' and Eastern as 'holistic'. The aim is rather modest - to help improve the therapeutic relationship by providing the practising clinician serving a multi-faith population with a better understanding of how individuals from these four faiths make sense and derive meaning from their emotional suffering. A few practical examples are given that can help make patients from these faiths feel understood and clinicians become cognisant of the inner world of their patients.

\section{Shared beliefs}

\section{Dharma (dhamma in Pali)}

Dharma has no English equivalent term, although it has been variously translated as religion, law, duty, morality, justice and righteousness. It is a broad category of overlapping concepts, defined by Franklin 
Edgerton as follows: 'Dharma is propriety, socially approved conduct, in relation to one's fellow men or to other living beings (animals, or superhuman powers). Law, social usage, morality, and most of what we ordinarily mean by religion, all fall under this head' (Underwood 1974). Dharma incorporates all these, and yet transcends distinctions among religion, ritual, law and ethics as understood in Western traditions. Dhamma, the Buddhist equivalent, implies truth, cosmic order and righteousness, as specifically taught by the Buddha.

\section{Karma (Sanskrit for action)}

In all four faiths, every action is thought to have consequences which will affect the doer at some future time. This law of karma is distinct from the law of universal causation, which states that every action, event or contingent being is caused. Karma is specifically related to the effect of an action or intention on the doer; unlike actions that result from passions, desires or need for a particular result, disinterested actions are not karmic (Reichenbach 1988). Karma is integral to the concept of rebirth and reincarnation, also shared by all four faiths (Burley 2014). Karma is not, as commonly assumed, a signifier of passive acceptance of fate or destiny, but a requirement that a being with agency should think and act in accordance with dharma, and with a dispassionate attitude towards outcome. Just as a seed is not the cause of a tree, karma is not 'mechanically' causal but instead implies the fructification of one's deeds. The theory and practice of karma is explored in detail in the Bhagavad Gita, another central text of Hinduism (Easwaran 2007b).

\section{Samsara}

Samsara too has multiple meanings, such as the 'external world' and the 'cycle of birth and death', although etymologically its origin is from a root meaning 'wandering'. In all four faiths, a living being (jiva) is trapped within samsara consequent upon present and past actions (karma). In all four faiths, the being transmigrates between successive lives, although since there are profound differences in the concept of self (described below), there are important differences in what it is that transmigrates between births. Buddhists, for instance, do not believe in the existence of a permanent soul. Buddhist concept is therefore best described as rebirth of a flux of a mental stream tied to karma, rather than reincarnation: '[in Buddhist belief] it is not some identical entity (the soul) which passes from one to another place but the ever-changing forces which disappear in one state and appear in another' (Ketcham 2018). A popular Buddhist metaphor of rebirth is that it is like the flame from one candle lighting another.

Bhakti (devotion) refers to an emotional attitude and attachment of a devotee to God in Hinduism and Sikhism, and to Buddha in Buddhism (Buddha) and Tirthankaras (enlightened beings, spiritual leaders) in Jainism. The concept of bhakti is widespread across all faiths in India, including Sufi Islam, and is based on a loving relationship with God that leads to longing, often expressed in poetry and songs. Rituals, offerings, singing and veneration of sanctified places are common bhakti practices. Meditation or repeated utterances of holy words or phrases (mantras; shlokas) are also forms of bhakti.

\section{Maya (illusion)}

In all four faiths, phenomenal reality is distinguished from true reality. Maya is a powerful illusion that makes humans believe that phenomena represent reality, that the empirical is the real (Shastri 1911). Mayajaal (a web of illusions) traps human beings into forgetting their true nature and hence is a hinderance to liberation. The concept of maya does not deny empirical reality but implies a higher transcendent reality beyond empirical phenomena. In Indian philosophy, maya leads to a false perception of duality or difference; false in this context means sublated by correct awareness, as in the Hegelian notion of resolving opposites into a higher unity (Radhakrishnan 1923; Mishra 2001).

\section{Liberation}

In all four faiths, the state that breaks the cycle of rebirth, i.e. liberates the being from suffering, is the ultimate goal of existence. It is known as moksha in Hinduism and Jainism, nirvana in Buddhism and mukti in Sikhism. It is the highest state a being can attain and frees the being from all karmic debt. Although the path and processes that lead to this state vary between the faiths, the result - liberation from karma - is common to all four.

\section{Concept of mind}

Mental apparatus in Indian philosophy consists of three components: mana (the root for both 'mind' and 'man') is the seat of desire and emotion, buddhi is intellect or rationality (from which comes the word Buddha) and ahamkara (literally I-making; haumey in Punjabi) is the ego. The self, atman, is distinct from these three aspects of mental functions (described below).

Unlike Abrahamic religions, these Indian faiths do not make a clear distinction between a creator God 
that stands apart from his creation; instead, all of nature and cosmos is revered. The relationship between creator and creation is not like that between a painter (creator) and a painting (creation); instead, it is considered akin to that between a dancer and the dance. One depiction of the cosmos in Hinduism is Nataraja, the dancing Shiva/cosmic dancer (Fig. 1), which represents all that exists. In the Hindu world-view everything is suffused with 'Godliness'. Hence, Hindus worship animate and as well as inanimate entities. Buddhism considers questions about God to be meaningless. Buddha stated that worrying about God was like a man wounded with an arrow wanting to know the description of who had shot him, rather than seeking a cure for his affliction. Jainism does not believe in a creator God but accepts the existence of divine beings (see below). The Sikh belief in God is closest to the Abrahamic view, except that God in Sikhism exists in all of nature and is yet beyond space, time or form. Another important shared history of these faiths is the absence of forced conversion. Diversity of belief and religious pluralism are actively encouraged, and such tolerance and openness are particularly salient in Jainism and Sikhism.

\section{Hinduism}

There is no single religion known as Hinduism, and the word Hindu does not appear in any ancient Indian text. Terms such as India, Hindu and Hindustan originate in Middle Eastern and Western descriptions of the land and people living in the Indus valley (including Punjab and Kashmir), the Gangetic plains and the Deccan plateau (Lorenzen 1999). Several beliefs and practices are shared across the 1.35 billion adherents of Hinduism (about 16\% of the world population) and some are shared with other Indian religions, including Buddhism, Jainism and Sikhism (Doniger 2014). The correct term for this belief system is sanatana dharma (eternal law or way). Contrary to popular belief, Hinduism is not polytheistic. There is only one fundamental reality brahman (not to be confused with the caste Brahmin), which is both the cause and manifestation of all existence. Brahman is nirguna (without attributes) and transcendent but may become immanent sargun (with attributes). The thousands of deities worshipped by Hindus are the manifold names (naama), forms (roopa) and powers (shakti) of the same underlying fundamental reality. Hinduism does not have a founder or a single, doctrinal authority. The beliefs and practices of Hinduism arise from ancient Sanskrit texts dated 1500-800 BCE and include the shruti (that which is revealed, divine in origin), such as the Vedas, and the smriti (that which is remembered, orally transmitted between generations), such as itihasa (history).

There are several philosophical schools and traditions within Hinduism, but all emphasise the importance of ritual, and the caste system is embedded within most forms of Hinduism. For interested readers, one of the best books on Hinduism is by the first President of India and Oxford philosopher S. Radhakrishnan (Radhakrishnan 2016). There are excellent translations of the Bhagavad Gita and Upanishads by Easwaran (2007a, 2007b). Bartley's textbook on Indian religions is also recommended (Bartley 2010), as is The Cosmic Matrix (Mishra 2001).

\section{Buddhism}

The founder of Buddhism, the Buddha (born Siddhartha Gautama, also known as Shakyamunisage of the Shakyas) (Fig. 2) was born sometime between 6 th and 4 th century BCE to an aristocratic Hindu family in Lumbini, Nepal, and grew up in Kapilvastu, Northern India (Nandan 2013). Traditional biographies depict a thoughtful and introspective prince, who lived surrounded by luxuries, but on witnessing illness and the decrepitude of old age and death, began to question the meaning of existence. After renouncing the world and searching for the truth for years as an ascetic, he experienced enlightenment under a peepul tree (Ficus religiosa) in Bodh Gaya, Bihar, India. Under the patronage of King Ashoka (268-232 BCE), Buddhism spread through a network of overland and maritime routes between India, Southeast Asia, Central Asia, China and Japan, developing distinct philosophical schools and traditions (Emmerick 1987).

The doctrines of Buddhism are based on the teachings of Gautama Buddha and include 'the four noble truths': suffering (dukkha) is central to existence; this suffering is caused by craving and attachment (trishna); suffering can cease (nirvana); and the path to such cessation is 'eightfold'- the right views, right resolve, right speech, right conduct, right livelihood, right effort, right mindfulness and right concentration. Buddhism denies the existence of an independent, permanent self (anatma - no self). Instead, the Buddha emphasised transience of all phenomena, both physical and mental. All phenomena arise in interrelationships and dependence of causation (the law of dependent origination or conditionality, pratityasamutpada). Interested readers can find further details on the history and practices of Buddhism in Harvey (2013) and Strong (2015).

\section{Jainism}

Mahavir Jain, a contemporary of Buddha, was born into a royal family in Vaishali, present day Bihar, 


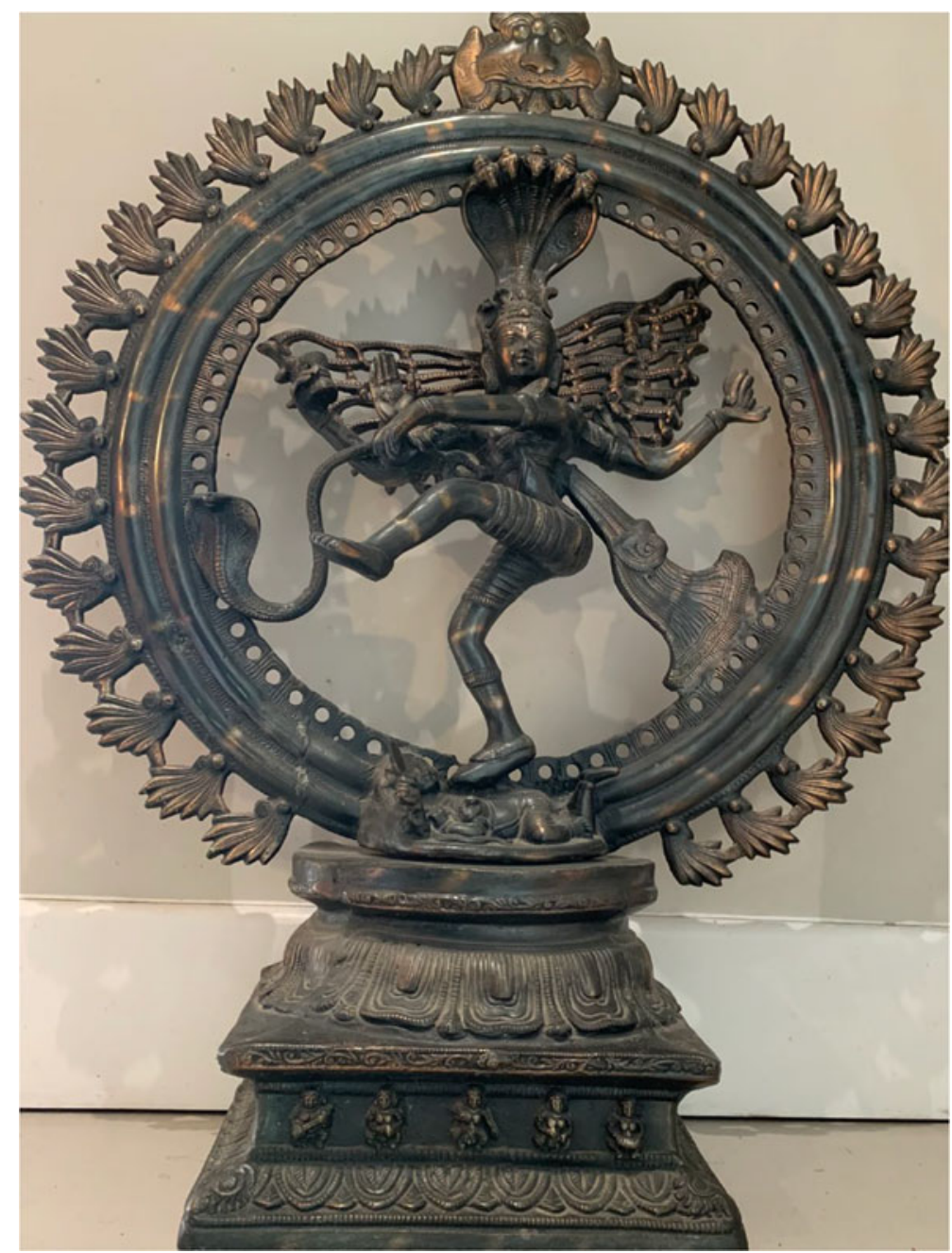

FIG 1

Nataraja, the cosmic dancer.

India (Fig. 3). Although considered the founder of Jainism, in Jain hagiography he is the last of 24 tirthankaras and responsible for giving Jainism its final form. Jains do not believe in a creator God or a created universe; instead, godliness (divinity) is considered inherent in every living being. The three core tenets of Jainism are ahimsa (nonviolence), anekantavada (non-absolutism; manifold thoughts) and aparigraha (non-attachment). Ahimsa is the highest duty: no being should be killed or harmed, regardless of the intention of an act. Jains are hence strictly vegetarian, some refusing to eat tubers or vegetables that must be pulled out of the ground (considered violence). Nonabsolutism implies a complete acceptance of plurality of belief systems and requires Jains to consider the views and beliefs of their rivals while questioning their own; the closest Western concept would be moral relativism. Jain doctrine places very strong emphasis on rationality and logic; Jainism has produced some of the finest mathematicians in ancient
India. For further details on Jainism, see Paniker (2011) and Babb (2015).

\section{Sikhism}

Sikhism is a relatively young religion. Its 20-30 million adherents are spread around the world (Hackett 2012), with the majority living in Punjab, India. Its founder Guru Nanak (1469-1539) (Fig. 4) was born to a Hindu family in Nankana Sahib, now Pakistan, during a period of interethnic strife caused both by Mughal rulers forcibly converting the local population to Islam and intercaste conflict within Hinduism. Nanak was interested in spiritual matters from an early age, and in early adulthood he set off on a spiritual quest with the statement 'I am neither a Hindu nor a Muslim', implying unity of all humankind. He insisted that the divine is one (Ek Omkar - one creator), all human beings are equal and different religions are like rivers leading to the same ocean 


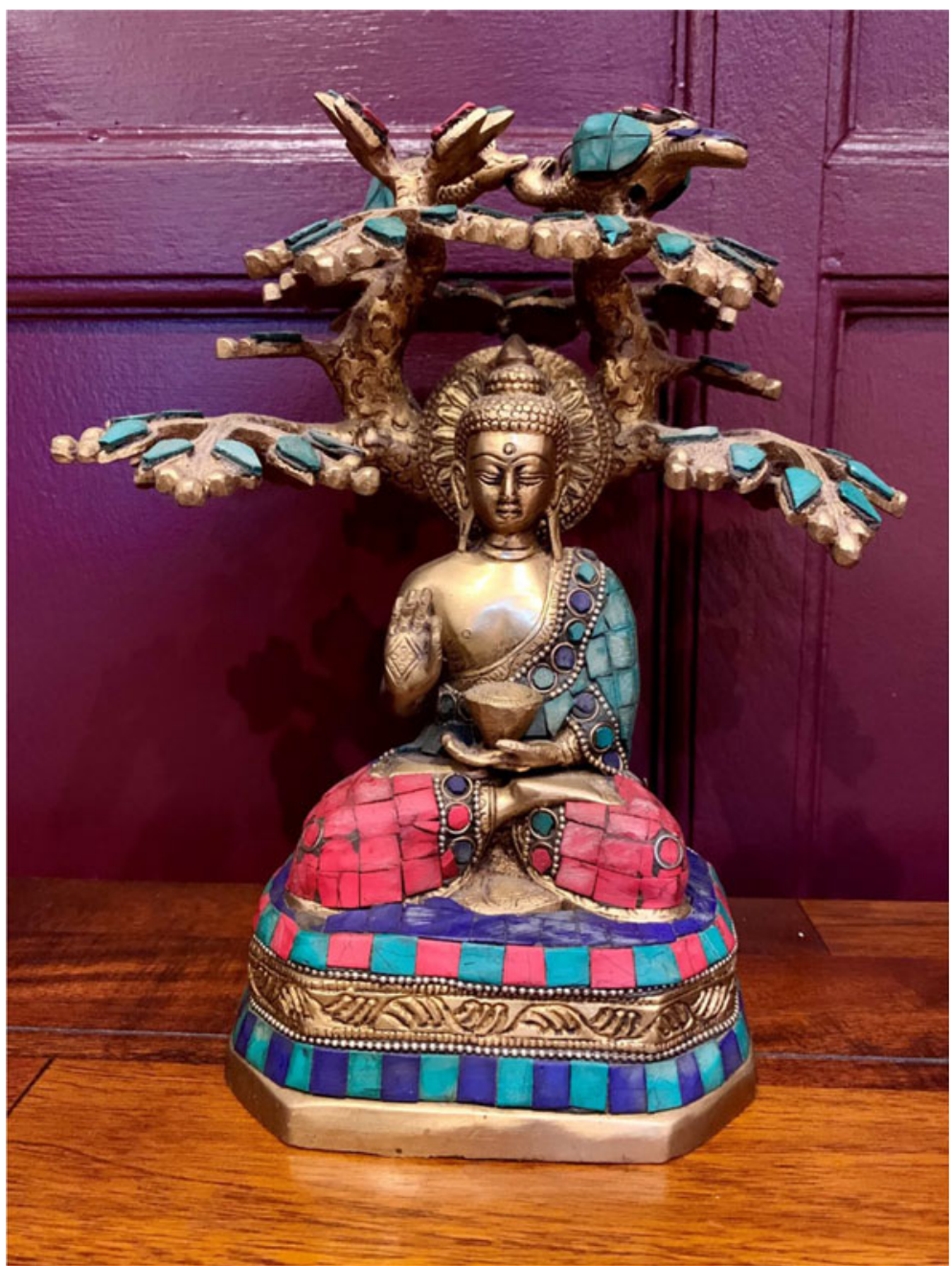

FIG 2 The Buddha, Gautama Siddhartha.

of truth. Human beings need not renounce the world, be ascetic or indulge in worship of idols or rituals, but instead can live a spiritual life while contributing to society. The three main tenets of Sikhism are wand chhako (share what you consume), kirat karo (do good deeds) and Naam Japo (meditate on God). His followers were called Sikhs (from Sanskrit shishya, meaning pupil). Sikhs reject the caste system, ascribe complete equality between genders (traditionally all Sikh first names are gender neutral) and do not worship idols. Sikhs do not believe that God appears on earth in human form.

Besides the three core tenets described earlier, Sikhs believe in selfless service (seva), overcoming five impulses - kam, krodh, lobh, moh and ahamakar (lust, anger, greed, attachment and ego) - and practising humility (nimrata). As Sikhism spread under ten successive Gurus (spiritual teachers), its influence was violently repressed by Mughal kings, including the torture and beheading of some of the Gurus. The tenth Guru Gobind Singh created an army of the pure (Khalsa) best represented by contemporary turban-wearing Sikhs. The teachings of Sikh Gurus, along with poems and hymns of contemporaneous Bhakti movement saints of both Hindu and Muslim faiths, are compiled in the Guru Granth Sahib, the Sikh holy book, which is treated as a 'living Guru'. Khushwant Singh (2005b) has written a comprehensive two-volume history of Sikhs and Sikhism.

\section{Concept of self}

William James distinguished 'me' from 'I': the former is self as object and the latter is self as subject, the experiential self (James 1890). Three centuries earlier, Descartes, doubting every mental phenomenon, concluded that he could not doubt the fact of his doubting, leading to the famous statement 'cogito ergo sum' ('I think, therefore I am'). The self was the thinking thing (res cogitans), the rest was the extended thing (res extensa) (Newman 2019). At least three millennia before Descartes, 


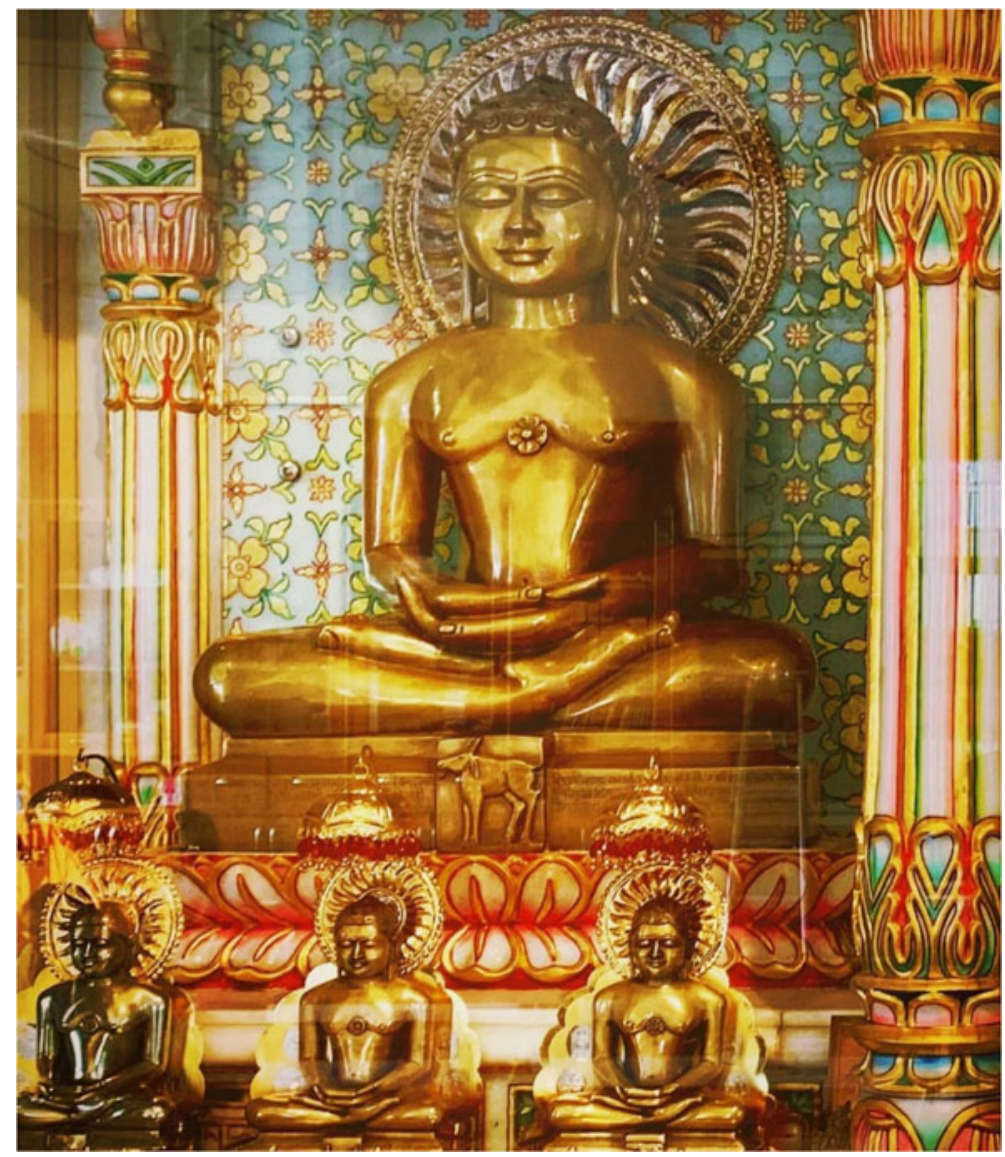

FIG 3 Mahavir Jain.

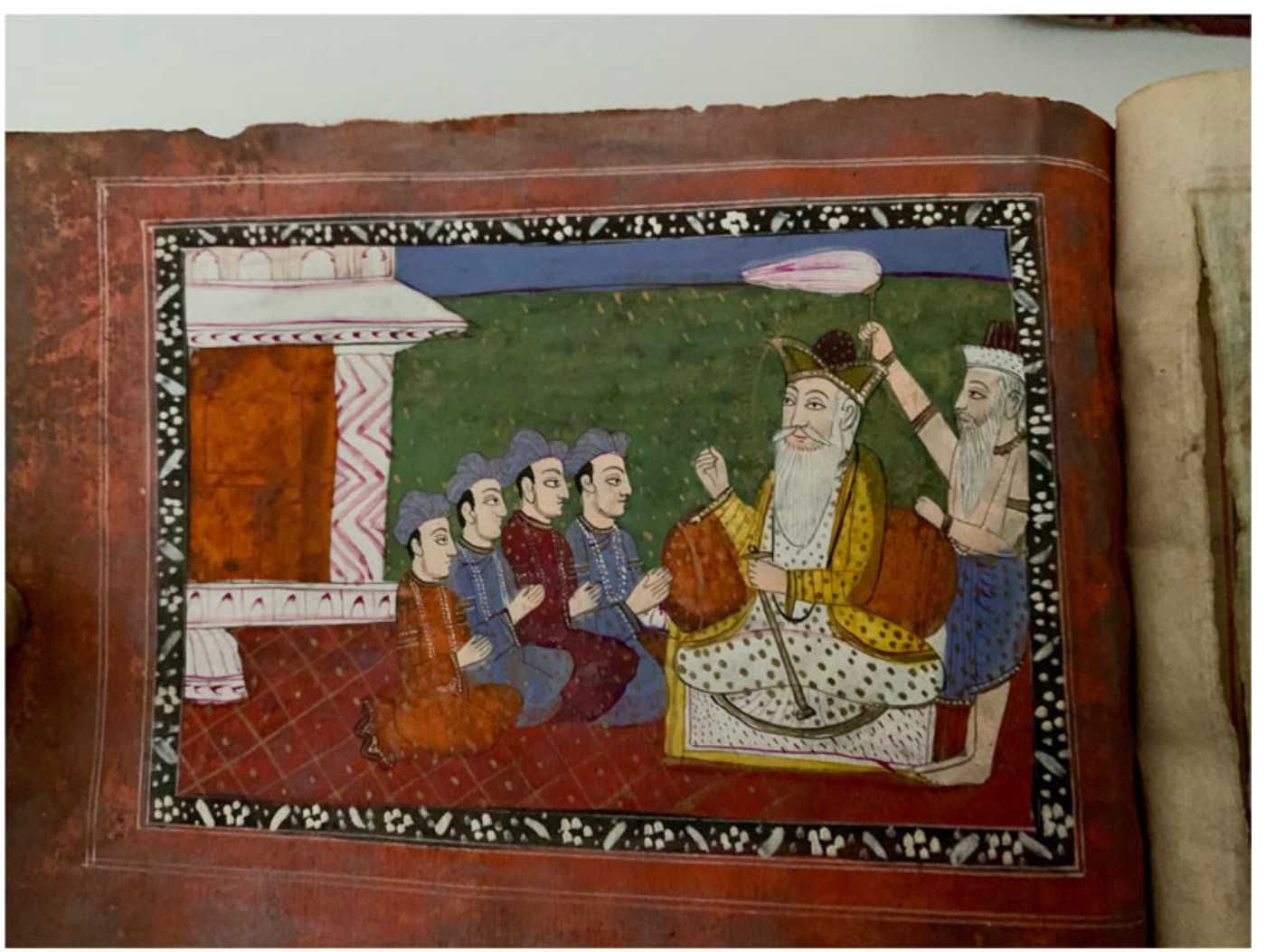

FIG 4 Guru Nanak (from an early 19th-century Sikh manuscript). 
Indian rishis (sages) had also attempted to understand the fundamental nature of both external reality and consciousness using a similar process of doubt and negation - neti neti, literally 'not this, not this' (Radhakrishnan 1923; Dura 2018). Unlike Descartes, the rishis did not consider the thinking thing (res cogitans) as the self. They instead concluded that the knower was distinct from what was known and the process of knowing. Since even our thinking can be observed, there must be an observer self, which experiences all mental functions (emotions, perceptions, cognition and volition) but is distinct from all these. This self is called the atman (soul or self) and is the witness-consciousness sakshi (Varma 2002; Radhakrishnan 2016).

Hinduism, Jainism and Sikhism all accept the existence of atman as the underlying, fundamental and immutable self, although there are subtle differences in how the term is understood and integrated with the rest of their belief systems. In Jainism, atman is one of the fundamental substances making up the universe. All sentient beings possess an atman. Buddhism, however, denies the existence of an individual self, instead considering the idea of a permanent self, like all other phenomena, as transient and illusory (anatma). When Hindu sages looked inwards, they found the atman. Their Buddhist counterparts found shunyata (zero, void, non-existence) instead.

\section{Suffering}

In all four religions, the term dukkha is used to imply suffering, although its wider meaning includes distress, dissatisfaction, unhappiness and sorrow. In all four, the main causes of suffering are craving, desire or attachment (trishna), the 'unfolding' of karmic debt and ignorance of the real nature of reality (avidya, or ignorance). Although the Hindu concept of dukkha pre-dates Buddhism, dukkha is much more salient in the latter belief system: life as suffering is one of the four core tenets of Buddhism. Liberation is available by following the path of dharma, accepting transience of all phenomena as well as their emptiness, and spiritual awakening with cultivation of detached equanimity that does not change with circumstances. Sikhism describes several causes of suffering, from bad karma to doubt (bharam), ignorance, grief and emotional wounds. Sikhs believe that everything happens because of a divine command, and hence God is the ultimate destroyer of suffering - dukkha bhanjan (Kalra 2012).

Sikhism has a unique concept of a positive mental state - chardi kalaa (spirit in ascension). For all its existence, followers of Sikhism have had to fight wars and invasions, usually against overwhelming odds, Punjab being the main land route into India.
Chardi kalaa is a state of joy and optimism which asks Sikhs to remain in a state of dignified acceptance, no matter how severe the hardships of life. Sikhs are asked to never despair, never admit defeat and never harbour enmities. Every Sikh prayer ends with the phrase: Nanak naam chardi kalaa, terey bhaney sarbat da bhalla (Nanak's name endows a state of joy, by your grace may everyone prosper).

\section{Therapeutic implications}

Studies suggest that many patients with mental illness wish to discuss religious beliefs and spirituality as part of the therapeutic process (MoreiraAlmeida 2014; Islam 2015, 2021; Koenig 2020). In practice, there are significant ethical and practical concerns in integrating spirituality or religion into routine clinical care, which were discussed in a series of papers in the 2008 issue of Psychiatric Bulletin (Hollins 2008; Koenig 2008; Poole 2008). Personally, I believe that psychiatrists should not impose any belief system - religious, ideological, political or moral - on their patients. The potential for influencing vulnerable patients and breaching the doctor-patient relationship boundary are legitimate concerns (Poole 2011). Doctors rightly feel uncomfortable encroaching into such personal matters with patients (Best 2016).

However, since a central aim of clinical medicine, including psychiatry, is to alleviate suffering, understanding the patient's perspective on their suffering and exploring the meaning they ascribe to such suffering can strengthen the therapeutic relationship in a positive manner. Patients, first and foremost, want to feel understood. Clinicians should aim to make them feel understood, especially on deeply personal and spiritual aspects of their being. According to Cassel, 'physicians' failure to understand the nature of suffering can result in medical intervention that (though technically adequate) not only fails to relieve suffering but becomes a source of suffering itself' (Cassel 1982).

Studies have shown that although many patients wish to discuss spiritual matters with their doctors, doctors do not consistently inquire about patients' spiritual or religious beliefs (Islam 2015, 2021; Rosmarin 2015; Best 2016). When comparing psychiatrists with indigenous healers, Torrey (1986) described four essential ingredients that assist in healing: a shared world-view that provides meaning to a diagnosis, or the 'naming process'; personal qualities of the clinician that facilitate recovery; positive patient expectations (hope, faith, placebo, etc.); and patients feeling a sense of empowerment or mastery as part of the interaction. One way to bridge the ethnic or cultural divide between a patient and a clinician is for the latter to understand the former's 
world-view, so that, as far as possible, a shared sense of meaning can be created. Such a shared sense does not mean simply agreeing with a patient or colluding in what may be a delusional or dangerous belief, but finding a common ground on how a patient makes sense of their distress and suffering.

During a home visit for a young man with psychosis, I realised the power of faith and belief in engaging people. This young man was adamant that he was not ill but possessed by a djinn (a malevolent spirit); he believed that he needed to be a better and more devout Muslim rather than see our team or take medication. He specifically wanted Allah's forgiveness for any sins he might have committed. As our conversation about the need for biomedical care reached a stalemate, his father intervened: 'Allah may have sent this doctor to see you. Allah also helps humans make medication. Have you considered that Allah might have answered your prayer and that is why this doctor is here?' That was the therapeutic breakthrough we needed, and a critical juncture in his subsequent recovery. The father created a shared sense of meaning between that young man's predicament and our ability to help him.

As part of a comprehensive clinical history, I always ask patients about their religious background and whether they are devout. I also ask them what they believe is happening to them. Patients have diverse causal explanations, from 'I don't know', stress, physical ill health and social circumstances to religious and spiritual explanations. Where appropriate, I use my knowledge to explore their subjective meaning and help them feel that I understand their suffering. My patients are often acutely unwell with psychosis - frightened, indifferent or actively hostile to psychiatric care - and helping them realise that I am on their side is a prerequisite for successful engagement with care. If a patient asks me about my personal beliefs, I admit that although born in the Sikh faith, I am not a practising Sikh but am interested in diverse spiritual traditions. If spirituality or faith do not emerge as important matters in the clinical picture or in the management plan, I see no necessity or requirement to raise them. I have rarely felt the need to be cautious; instead, I have found that patients appreciate my raising these matters in a spirit of gentle inquiry and 'harmless inquisitiveness' (Koenig 2020).

Medical curricula in the UK have started including teaching about spirituality (Neely 2008; Culatto 2015). Such teaching need not negate or conflict with any other aspect of medical training (Calman 2008). The Royal College of Psychiatrists in the UK has published a position statement on spirituality and psychiatry with guidance for clinicians and trainees (Royal College of Psychiatrists
2013), and other guidelines are available (Royal Australian and New Zealand College of Psychiatrists 2018; Koenig 2020), including a review of guidelines (Moreira-Almeida 2014). The UK guidelines suggest that 'spirituality and religion are at least factors about which psychiatrists should be knowledgeable, insofar as they have an impact on the aetiology, diagnosis and treatment of mental disorders' (Royal College of Psychiatrists 2013: p. 6). Such knowledge need not be extensive; for example, just knowing the term dukkha can be valuable to a clinician treating a patient from one of these Indian religions. The word can also be used while assessing mood. One does not need linguistic fluency in an Indian language; the word can be used within an English sentence: 'are you feeling dukkha?' It works not just with patients with limited English, but also second-generation or English-fluent patients of Indian origin, and they respond very differently to this as opposed to 'are you depressed?', since dukkha has cultural meaning well over and above a simple translation of depression.

With a Sikh patient describing their distress, I can remind them of the phrase from a Sikh hymn 'Nanak dukhiya sub sansaar' ('O Nanak, all the world suffers'). I immediately sense a shift in the patient's level of trust and confidence in the relationship. When engendering hope, I remind Sikh patients of the importance of chardi kalaa. In patients of all four faiths, when appropriate I discuss the concept of detachment, including detachment from suffering. This neither minimises nor denies their suffering; instead, it seeks to promote resilience and aims for an equanimous acceptance with grace.

Using the term mana as the seat of emotions, or buddhi while discussing cognitive functions, allows better access to patients' understanding of their affliction than is sometimes allowed by medical terminology. Clinicians cannot be expected to have in-depth understanding of the multitudes of cultural belief systems of their patients in today's multicultural societies. I feel lucky being multilingual and growing up in the secular and pluralistic Indian tradition. But learning a little bit about the majority faiths in the UK, especially terms for distress and suffering, is not beyond any interested clinician.

Culture is not a static or impermeable barrier between people, or a conflict-laden system that necessarily divides people or sets one group against another. Human suffering is universal, and the focus of clinical psychiatry should be on what unites us rather than what divides us. This requires a fundamental shift in how we view difference - be it ethnic, cultural or class based. A practice heavily focused on 'difference' rather than on universality both hinders learning and makes people wary of engaging in what is seen as contentious and hence best avoided 
MCO answers

1 e 2 c 3 a 4 e 5 e
(Kai 1999, 2001). As the most culturally and ethnically diverse branch of medicine in the UK, psychiatry should see its diversity as a strength that other branches of medicine might emulate.

\section{Research implications}

Ethnicity, race and culture have been contentious in mental health research and often divisive (Singh 2009). Much of the attention has focused on the epidemiology and pathways to care, especially for patients from the Black ethnic group, although there has been some research on patients of Islamic faith as well (Singh 2013, 2015; Islam 2015). There are very few data on the mental health of British citizens from one of these four Indian religious groups, although one study showed that British Indian adolescents had better mental health than their White counterparts (Dogra 2013). We do not have robust data on the incidence and prevalence of mental ill health in these communities and on whether they too experience adverse pathways into psychiatric care. We do not know about their help-seeking behaviours or whether public education campaigns need to be culturally contextualised and framed in language and terminology that speaks to these communities. We do not know whether services meet their needs, and if not, how and why services might need to change. As British society becomes more diverse, our services will have to adapt to meet the needs of all our communities. Beliefs about mental health, illness and suffering are deeply intertwined with religious beliefs, and clinicians will do a disservice to patients if they ignore this important aspect of their world-view and deal with their distress purely as a medico-technological problem.

\section{Conclusions}

The reasons why psychiatrists are reluctant to discuss religion and spirituality with their patients are well-rehearsed and entirely understandable. Race, culture and ethnicity are contentious enough already, and many psychiatrists will wish to avoid introducing another complex topic into the clinical encounter, especially one that may be interwoven with the patient's psychopathology (e.g. religious delusions). In today's secular age, religious beliefs and observance are not central to the lives of many people who seek psychiatric care, although these may be important for minority ethnic groups. I have argued that spirituality can and should be explored where appropriate, although discussions about spirituality should neither be enforced nor prioritised over any compelling clinical factors. A basic understanding of a few salient concepts of the main religions of the world (in this article,
Indian religions) can foster greater understanding in the therapeutic relationship and nourish engagement.

\section{Acknowledgements}

I am grateful to Professor Rob Poole for his comments on successive drafts of this article. Ms Ariana Kular kindly helped me with the citations.

\section{Funding}

S.P.S. is part-funded by the National Institute for Health Research (NIHR) Applied Research Collaboration (ARC) West Midlands. The views expressed are those of the author and not necessarily those of the NIHR or the Department of Health and Social Care.

\section{Declaration of interest}

None.

\section{References}

Babb LA (2015) Understanding Jainism (Understanding Faith). Dunedin Academic Press.

Bartley C (2010) An Introduction to Indian Philosophy. Continuum.

Best M, Butow P, Olver I (2016) Doctors discussing religion and spirituality: a systematic literature review. Palliative Medicine, 30: 327-37.

Burley M (2014) Karma and rebirth in the stream of thought and life. Philosophy East and West, 64: 965-82.

Calman K (2008) Spirituality and medical education. Medical Education, 42: $123-5$.

Cassel EJ (1982) The nature of suffering and the goals of medicine. New England Journal of Medicine, 306: 639-45.

Culatto A, Summerton CB (2015) Spirituality and health education: a national survey of academic leaders UK. Journal of Religion \& Health, 54: 2269-75

Dogra N, Svirydzenka N, Dugard P, et al (2013) Characteristics and rates of mental health problems among Indian and White adolescents in two English cities. British Journal of Psychiatry, 203: 44-50.

Doniger W (2014) On Hinduism. Oxford University Press.

Dura I (2018) "Defining the indefinable": the hermeneutics of the Upanishadic negation neti, neti in Sankara's apophatic theology. In Proceedings of the XXIII World Congress of Philosophy (vol 16) (ed K Boudouris): 89-94. Philosophy Documentation Center.

Easwaran E (2007a) The Bhagavad Gita. Nilgiri Press.

Easwaran E (2007b) The Upanishads. Nilgiri Press.

Emmerick R (1987) Buddhism in Central Asia. In Encyclopedia of Religion, Vol. 2 (ed M Eliade): 400-404. Macmillan.

Hackett Conrad (2012) The global religious landscape. Pew Research Center.

Harvey P (2013) An Introduction to Buddhism: Teachings, History and Practices. Cambridge University Press.

Hollins S (2008) Understanding religious beliefs is our business. Invited commentary on... Religion and mental health. Psychiatric Bulletin, 32: 204.

Islam Z, Rabiee F, Singh SP (2015) Black and minority ethnic groups' perception and experience of early intervention in psychosis services in the United Kingdom. Journal of Cross-Cultural Psychology, 46: 737-53. 
Islam Z, Rabiee-Khan F, Singh SP (2021) Culture and spirituality in the process of mental health and recovery: users and providers perspectives. Diversity and Equity in Health and Care, 18: 425-9.

James W (1890) The Principles of Psychology. Henry Holt and Co.

Kai J, Spencer J, Wilkes M, et al (1999) Learning to value ethnic diversity - what, why and how? Medical Education, 33: 616-23.

Kai J, Bridgewater R, Spencer J (2001) '“Just think of TB and Asians", that's all I ever hear': medical learners' views about training to work in an ethnically diverse society. Medical Education, 35: 250-6.

Kalra G, Bhui KS, Bhugra D (2012) Sikhism, spirituality and psychiatry. Asian Journal of Psychiatry, 5: 339-43.

Ketcham C (2018) Schopenhauer and Buddhism: soulless continuity. Journal of Animal Ethics, 8: 12-25.

Koenig HG (2008) Religion and mental health: what should psychiatrists do? Psychiatric Bulletin, 32: 201-3.

Koenig HG, Peteet JR, VanderWeele TJ (2020) Religion and psychiatry: clinical applications. BJPsych Advances, 26: 273-81.

Lorenzen DN (1999) Who invented Hinduism? Comparative Studies in Society and History, 41: 630-59.

Mishra R (2001) The Cosmic Matrix: In the light of the Vedas. Rupa \& Co.

Moreira-Almeida A, Koenig HG, Lucchetti G (2014) Clinical implications of spirituality to mental health: review of evidence and practical guidelines. Revista Brasileira de Psiquiatria, 36: 176-82.

Nandan GB, Jangubhai NAM (2013) The comparative study between Hinduism and Buddhism. International Journal of Humanities and Social Science Invention, 2(5): 27-31.

Neely D, Minford EJ (2008) Current status of teaching on spirituality in UK medical schools. Medical Education, 42: 176-182.

Newman L (2019) Descartes' epistemology. Stanford Encyclopedia of Philosophy Archive, Spring (https://plato.stanford.edu/archives/spr2019/ entries/descartes-epistemology/).

Office for National Statistics (2013) 2011 Census: Key Statistics and Quick Statistics for Local Authorities in the United Kingdom. ONS (https://www. ons.gov.uk/peoplepopulationandcommunity/populationandmigration/ populationestimates/bulletins/keystatisticsandquickstatisticsforlocalauthoritiesintheunitedkingdom/2013-10-11).

Paniker A (2011) Jainism: History, Society, Philosophy and Practice. Motilal Banarsidass Publishing House.
Poole R, Higgo R, Strong G, et al (2008) Religion, psychiatry and professional boundaries. Psychiatric Bulletin, 32: 356-7.

Poole R, Higgo R (2011) Spirituality and the threat to therapeutic boundaries in psychiatric practice. Mental Health, Religion \& Culture, 14: 19-29.

Radhakrishnan S (1923) Indian Philosophy. Macmillan Company.

Radhakrishnan S (2016) The Philosophy of Hinduism. Niyogi Books.

Royal Australian and New Zealand College of Psychiatrists (2018) The Relevance of Religion and Spirituality to Psychiatric Practice (Position Statement 96). RANZCPC.

Reichenbach BR (1988) The law of karma and the principle of causation. Philosophy East and West, 38: 399-410.

Rosmarin DH, Forester BP. Shassian DM, et al (2015) Interest in spiritually integrated psychotherapy among acute psychiatric patients. Journal of Consulting and Clinical Psychology, 83: 1149-53.

Royal College of Psychiatrists (2013) Recommendations for Psychiatrists on Spirituality and Religion (Position Statement PS03/2013). RCPsych.

Shastri PD (1911) The Doctrine of Maya. Luzac and Co.

Singh P (2005a) Hindu bias in India's 'secular' constitution: probing flaws in the instruments of governance. Third World Quarterly, 26: 909-26.

Singh K (2005b) History of the Sikhs (Vol 1 \& 2). Oxford University Press.

Singh SP (2009) Shooting the messenger: the science and politics of ethnicity research. British Journal of Psychiatry, 195: 1-2.

Singh SP, Islam Z, Brown L, et al (2013) Ethnicity, detention and early intervention: reducing inequalities and improving outcomes for black and minority ethnic patients: the ENRICH programme, a mixed-methods study. Programme Grants for Applied Research, 1(3).

Singh SP, Brown L, Winsper C, et al (2015) Ethnicity and pathways to care during first episode psychosis: the role of cultural illness attributions. BMC Psychiatry, 15: 287

Strong J (2015) Buddhisms: An Introduction. Oneworld Publications.

Torrey EF (1986) Witchdoctors and Psychiatrists: The Common Roots of Psychotherapy and Its Future. HarperCollins.

Underwood FB (1974) Notes on conscience in Indian tradition. Journal of Chinese Philosophy, 2: 59-65.

Varma PK (2002) Adi Shankaracharya: Hinduism's Greatest Thinker. Tranquebar. 
MCOs

Select the single best option for each question stem

1 As regards Indian religions:

a unlike Abrahamic religions, all Indian religions are polytheistic

b all Indian religions believe in the theory of karma and reincarnation

c Sikhs do not believe in idol worship

d all religions are based on the caste system

e non-violence (ahimsa) against living beings is the primary focus of Jainism.

\section{Patients' spiritual beliefs are important} because:

a these are reflected in their psychopathology

b doctors and patients should be of the same faith for the therapeutic relationship to be strong

c in devout patients, help-seeking can be determined by their spiritual understanding of their experiences

d clinicians must avoid exploring sensitive areas such as the patient's religion and spiritual belief

e spiritual treatments are essential for many psychiatric conditions.
3 In the Indian concept of suffering:

a suffering is an inevitable part of existence

b suffering is an illness of the mind that requires Ayurvedic treatment

c suffering is intricately tied to belief in the theory of reincarnation

d suffering is the same as depression and considered a biomedical disorder

e suffering is only a part of Buddhist philosophy and religion.

4 The law of karma implies that:

a human actions have no impact on what is determined by fate or destiny

b all actions have similar karmic consequences, regardless of the motivation or intention of the doer

c strict determinism is supported by Indian religions

d empirical reality does not exist; hence, actions have no long-term consequences

e human actions must be motivated by good intentions, rather than by expectation of good outcomes.
5 Western and Indian concepts of mind differ because:

a emotions and cognition are considered part of the same phenomena in Indian systems

b mind is considered the same as intellect

c what is known as superego in the West is called religion in India

d buddhi (rationality) is considered as the controller of the self in the Indian system

e mind-body dualism is not central to the understanding of distress in Indian religions. 